\title{
Can you find the golden ratio in your plate?
}

\author{
Ophelia Deroy $^{1 *}$ and Charles Spence ${ }^{2}$
}

\begin{abstract}
A scientific approach to plating needs to be based on perceivers' responses and anticipate possible cultural and individual differences. It cannot just follow common sense principles, whose validity remain untested and only attract journalists' attention, like the claim that people will prefer food composition based on the golden ratio.
\end{abstract}

Keywords: Plating, Aesthetics, Colour, Composition, Psychology, Visual perception

\section{Introduction}

According to the latest scientific research, the visual appearance of a dish can affect how much diners like it, and even how they rate its overall flavor [1]. Whereas the majority of the research that has been published to date has focused on how specific properties, such as the colour of individual ingredients, can influence people's evaluation, the understanding of the visual appeal of a dish [2], such as a curry, with sauce, vegetables, and rice, undoubtedly needs to take into account the composition of the various elements on the plate [3-6]. According to Dr Hadley, a physicist at Warwick University's Department of Physics (Coventry, UK), applying a mathematical formula can tell you exactly how much rice and curry will look appealing to all consumers. A plate size of $27 \mathrm{~cm}$, with a $23 \mathrm{~cm}$ diameter bed of rice precisely $5 \mathrm{~mm}$ thick, and supporting a low dome of curry with a diameter of $14 \mathrm{~cm}$ and a maximum height of $2.4 \mathrm{~cm}$, represents, or at least so Dr Hadley would like to have us believe, the perfect presentation for a plate of curry, and should be liked by everyone. Other variants of the perfect curry can be envisaged, with equal precision, for a hungry student or an aficionado of nouvelle cuisine [7]. The press have certainly jumped enthusiastically onto this story $[8,9]$.

The calculations applied here are supposed to satisfy what is known as the golden ratio, the ratio whereby the relation of the greater part to the sum of the two parts equals that of the two parts. To have the most aesthetically pleasing curry, then, the supposition is that the rice must be approximately 1.61 times wider than the circle of curry that is laid on top $((\sqrt{5}+1) / 2$, to be exact $)$. Of

\footnotetext{
* Correspondence: ophelia.deroy@sas.ac.uk

'Centre for the Study of the Senses, University of London, London, UK

Full list of author information is available at the end of the article
}

course, here one needs to grant Dr Hadley the right to extend the concept of the golden ratio, usually meant to apply to rectangles and ellipses, to the relation between the radiuses of two circles. It is also not meant to explain the aesthetics of three dimensional objects, and apply to the height of objects, like here.

Is a claim that plates should obey the golden ratio science or enigmatic calculation? Are we not sprinkling some mysticism back onto the plate? In the past, a number of authors have supposed that the golden ratio dictates a viewer's preference for certain architectural achievements or visual displays (not to mention to be a proof of God's mathematical skills [10-12]). However, careful scientific research has demonstrated that this magical number actually explains little of the sense of balance and harmony that people typically attribute to shapes or composition. Despite some optimistic early results with rectangles ([13-16], but see [17]), Fechner, one of the fathers of modern psychology, failed to find any evidence that people actually preferred ellipses built on the golden ratio rather than others [18]. Furthermore, specialists in the field of experimental aesthetics have since demonstrated that many other factors bear on what people think has a balanced composition or harmonious figure $[19,20]$.

What such research has demonstrated is that what counts as a balanced composition depends to a large degree on what is represented or presented, and preferences will differ for different shapes, colours, and objects $[21,22]$. In this sense, preferences for curry and rice might not be the same depending on whether it is a green or a red curry. Aesthetic preferences, if one chooses to extend them to the plating of food, will also vary with context [23] and present individual differences. 
If this is true for simple geometrical shapes, with different groups of individuals expressing markedly different preferences when it comes to judging the most beautiful of rectangles [20,24], it is also likely to be true when it comes to a plate of curry. Instead of the myth of the golden ratio, the reality will likely depend on the diner's cultural background, whether they happen to be hungry or not, the types of plating arrangements that they have been exposed to previously, and perhaps even their personality (see McManus et al. for a recent investigation of simple compositions [25]). The first thing to do, of course, would be to measure these preferences directly, by asking people to select the most pleasing or appetizing plate of curry (online testing might be useful here). This can be done at minimal cost, by any reasonable marketing department. If science needs to be involved, it will be to make sure that the presented pictures systematically vary along key dimensions, and that important interactions between, for example, size, colour, orientation, and so on, are not ignored.

Ignoring which science is relevant to the choice of the perfect plating, or the elaboration of the perfect meal, is perhaps the biggest problem at the present time. A plate needs to be resistant, smooth, and perhaps shiny, and physics and design may certainly be relevant. Students of physics might also be able to describe how to provide an equal distribution of weight in the plate if it is to be filled with a certain quantity of low-density rice and high-density curry. But when it comes to the preferences of diners, equations and simple premises are just not that relevant. It is rather the discovery of the fundamental premises themselves which is at the core of the work in this area, or at least it should be. As mentioned, many studies in experimental psychology were needed to show that the golden ratio does not necessarily represent a useful guide to people's visual preferences. Many more experiments are being performed, even today, in order to try and gain a better understanding of what governs the sense of balance or harmony in visual composition. It will take many more psychologists and careful testing to demonstrate what drives the preferences of consumers once the visual composition is also supposed to be eaten, as it is the case for a combination of curry and rice on a plate.

Take, for example, Hadley's claim that diners want a clear rim of at least $2 \mathrm{~cm}$ around the food on the plate. This is certainly not the case in the most admired Michelin-starred plating styles, where beautifully arranged sauces and spices cover all the plate's surface; and why would it be $2 \mathrm{~cm}$ rather than $3 \mathrm{~cm}$ or $5 \mathrm{~cm}$ ? Do preferences depend on the color, the size, or even the shape of the plate, and the type of food that it contains? Is it the same for desserts, coming at the end of the meal, and starters? Dr Harvey's research [26] certainly rests on intuitive aesthetic principles, which explain why the final result (the 'perfect curry') will indeed look appealing enough to a large body of individuals.

Given the role played by intuition in this research, one would rather trust the chef's intuitive sense of presentation. Claims that chefs and cooks 'have been getting curry all wrong', as reported in The Times, is not just provocative, but totally misplaced [8]. The development of a scientific approach to the presentation of food, in all its cultural, aesthetic, and individual complexity [3], is a noble prospect. For this very reason, we need more than merely the feeding of intuitions into complex equations. We certainly need more experimental rigor and to put the diners at the centre of our scientific investigation of the aesthetics of plating [27]. Not magic numbers.

\section{Competing interests}

The authors declare that they have no competing interests.

\section{Authors' contribution}

$\mathrm{OD}$ and CS contributed equally to this manuscript. Both authors read and approved the final version of the manuscript.

\section{Acknowledgements}

OD and CS are supported by an Arts and Humanities Research Council (AHRC) grant in the 'Science in Culture' theme (re-thinking the senses).

\section{Author details}

${ }^{1}$ Centre for the Study of the Senses, University of London, London, UK. ${ }^{2}$ Crossmodal Research Laboratory, Department of Experimental Psychology, Oxford University, Oxford, UK.

Received: 12 November 2013 Accepted: 3 February 2014 Published: 3 March 2014

\section{References}

1. Spence C, Piqueras-Fiszman B, Michel C, Deroy O: Plating manifesto (II): the art and science of plating. Flavour. in press.

2. Lyman B: A Psychology of Food, More Than a Matter of Taste. New York, NY: Avi, Van Nostrand Reinhold; 1989.

3. Zampollo F, Wansink B, Kniffin KM, Shimuzu M, Omori A: Looks good enough to eat: how food plating preferences differ across cultures and continents. Cross Cult Res 2012, 46:31-49.

4. Zellner DA, Lankford M, Ambrose L, Locher P: Art on the plate: effect of balance and color on attractiveness of, willingness to try and liking for food. Food Qual Prefer 2010, 21:575-578.

5. Zellner DA, Siemers E, Teran V, Conroy R, Lankford M, Agrafiotis A, Ambrose $L$, Locher P: Neatness counts. How plating affects liking for the taste of food. Appetite 2011, 57:642-648.

6. Reisfelt HH, Gabrielsen G, Aaslyng MD, Bjerre MS, Møller P: Consumer preferences for visually presented meals. J Sens Stud 2009, 24:182-203.

7. Hadley M: The perfect curry. In Unpublished manuscript commissioned by Tilda Rice. Rainham: Tilda; 2013.

8. de Bruxelles S: Scientists find formula for the perfect curry. The Times, 1 November:45.

9. Griffiths S: Calculate your perfect CURRY: physicist creates formula to ensure the perfect ratio of rice to sauce when tucking into a korma. Mail Online 2013. [http://www.dailymail.co.uk/sciencetech/article-2481071/ Physicist-creates-formula-perfect-ratio-rice-sauce-tucking-curry.html]

10. Alberti LB: On the Art of Building. Cambridge, MA: MIT Press; 1989.

11. Ghyka M: The Geometry of Art and Life. New York, NY: Dover Publications; 1977.

12. Green CD: All that glitters: a review of psychological research on the aesthetics of the golden section. Perception 1995, 24:937-968.

13. Fechner GT: Zur Experimentalen Aesthetik [On Experimental aesthetics]. Leipzig: Hirzel; 1871.

14. Fechner GT: Vorschule der Aesthetik. [Introduction to Aesthetics]. Leipzig: Breitkopf \& Haertel; 1876. 
15. Fechner GT: Various attempts to establish a basic form of beauty: experimental, aesthetics, golden section, and square. Empir Stud Arts 1876, 15:115-130. Translation of chapter XIV.

16. Lalo C: L'esthetique Experimentale Contemporaine. [Contemporary Experimental Aesthetics]. Paris: Alcan; 1908.

17. Godkewitsch M: The 'golden section': an artifact of stimulus range and measure of preference. Am J Psychol 1974, 87:269-277.

18. Boselie F: The golden section has no special aesthetic attractivity! Empir Stud Arts 1992, 10:1-18.

19. McManus IC: The aesthetics of simple figures. Br J Psychol 1980, 71:505-524.

20. McManus IC, Weatherby P: The golden section and the aesthetics of form and composition: a cognitive model. Empir Stud Arts 1997, 15:209-232.

21. Boselie F: The golden section and the shape of objects. Empir Stud Arts 1997, 15:131-141.

22. Koneni $\mathrm{VJ}$ : The vase on the mantelpiece: the golden section in context. Empir Stud Arts 1997, 15:177-207.

23. Benjafield J, McFarlane K: Preference for proportions as a function of context. Empir Stud Arts 1997, 15:143-151.

24. Macrosson WDK, Strachan GC: The preference amongst product designers for the golden section in line partitioning. Empir Stud Arts 1997, 15:153-163.

25. McManus IC, Cook R, Hunt A: Beyond the golden section and normative aesthetics: why do individuals differ so much in their aesthetic preferences for rectangles? Psychol Aesthet Creativity Arts 2010, 4:113.

26. Anon: Academic reveals the secret to the perfect curry. Press release 2013

27. Deroy O, Michel C, Piqueras-Fiszman B, Spence C: The plating manifesto (I): from decoration to creation. Flavour. in press.

doi:10.1186/2044-7248-3-5

Cite this article as: Deroy and Spence: Can you find the golden ratio in your plate? Flavour 2014 3:5.

\section{Submit your next manuscript to BioMed Central and take full advantage of:}

- Convenient online submission

- Thorough peer review

- No space constraints or color figure charges

- Immediate publication on acceptance

- Inclusion in PubMed, CAS, Scopus and Google Scholar

- Research which is freely available for redistribution 